\title{
Avaliação da qualidade dos recursos hídricos no entorno de aterro controlado no munícipio de Santarém/Pará
}

A produção e disposição inadequada de resíduos sólidos têm se constituído um dos maiores problemas ambientais de todo o mundo. Desta forma, este trabalho teve como objetivo avaliar a qualidade das águas superficiais e subterrâneas do entorno do aterro controlado do município de Santarém-PA, a fim de identificar a presença de compostos nocivos ao meio ambiente. Foram analisados parâmetros físico-químicos e metais pesados, nas amostras de águas superficiais e subterrâneas em dois pontos próximos ao aterro e em duas lagoas dentro do aterro. Os resultados das análises físico-químicas e metais pesados, foram comparados com os parâmetros estabelecidos pela Resolução № 357 do Conselho Nacional de Meio Ambiente (CONAMA) e com a Portaria de Consolidação do Ministério da Saúde $\mathrm{N}^{\circ} 5$, para avaliar a qualidade da água superficial e subterrânea respectivamente. Os parâmetros analisados na água, como nitrato, pH, ferro e turbidez se mostraram fora dos padrões permitidos pela legislação, assim a água não está apropriada para nenhum tipo de uso ou atribuições estabelecidas pela legislação vigente. Já as análises de solo identificaram a presença de alguns metais pesados, em diferentes proporções. Para as o chorume as concentrações de nitrato, amônia, fósforo e mercúrio estão acima do permitido. A análise quali-quantitativa de solo mostrou que os elementos predominantes foram alumínio (Al), titânio (Ti), ferro (Fe) e silício (Si).

\section{Evaluation of the quality of water resources in the surroundings of controlled landfill in the municipality of Santarém/Pará}

\begin{abstract}
The inadequate production and disposal of solid waste has been one of the biggest environmental problems in the world. Thus, this study aimed to assess the quality of surface and groundwater surrounding the controlled landfill in the municipality of Santarém-PA, in order to identify the presence of compounds harmful to the environment. Physical-chemical parameters and heavy metals were analyzed in the samples of surface and groundwater at two points close to the landfil and in two ponds within the landfill. The results of the physical-chemical analyzes and heavy metals were compared with the parameters established by Resolution $\mathrm{N}^{\circ} 357$ of the National Environment Council (CONAMA) and with the Consolidation Ordinance of the Ministry of Health $\mathrm{N}^{\circ}$. 5, to assess the quality of the wate surface and underground respectively. The parameters analyzed in the water, such as nitrate, $\mathrm{pH}$, iron and turbidity were found to be outside the standards allowed by the legislation, so the water is not suitable for any type of use or attributions established by the current legislation. Soil analyzes identified the presence of some heavy metals, in different proportions. For the nitrate concentrations slurry, ammonia, mercury and phosphorous above are permitted. Qualitative and quantitative analysis of soil showed that the predominant elements were aluminum (Al), titanium (Ti), iron (Fe) and silicon (Si).
\end{abstract}

Keywords: Controlled landfill; solid residues; Water quality.

Topic: Engenharia Ambiental

Reviewed anonymously in the process of blind peer
Received: 04/10/2020

Approved: $\mathbf{2 4 / 1 1 / 2 0 2 0}$
Júlia Batista Dantas ir

Universidade Federal do Oeste do Pará, Brasil http://lattes.cnpq.br/9220370732716247

http://orcid.org/0000-0002-7447-2823

juh16maria@gmail.com

Vanessa Leão Peleja (iD

Universidade Federal do Oeste do Pará, Brasil

http://lattes.cnpq.br/4847354203016902

http://orcid.org/0000-0003-2138-3277

peleja.floresta@gmail.com

Joseph Simões Ribeiro (i)

Universidade Federal do Oeste do Pará, Brasil

http://lattes.cnpq.br/1888011247908339

http://orcid.org/0000-0001-9715-816X

josephribeiro@hotmail.com
Ruy Bessa Lopes (iD

Universidade Federal do Oeste do Pará, Brasil

http://lattes.cnpq.br/4195469692527946

http://orcid.org/0000-0002-4806-8835

ruybessa@yahoo.com.br

Lucinewton Silva de Moura (iD)

Universidade Federal do Oeste do Pará, Brasil

http://lattes.cnpq.br/2577499231565227

http://orcid.org/0000-0002-9266-946X

lucinewton.moura@yahoo.com.br
Referencing this:

DANTAS, J. B.; PELEJA, V. L.; RIBEIRO, J. S.; LOPES, R. B.; MOURA, L. S. Avaliação da qualidade dos recursos hídricos no entorno de aterro controlado no munícipio de Santarém/Pará. Revista Ibero Americana de Ciências Ambientais, v.11, n.6, p.383-392, 2020. DOI: http://doi.org/10.6008/CBPC2179-6858.2020.006.0031 


\section{INTRODUÇÃO}

A produção e disposição de resíduos sólidos têm se constituído um dos maiores problemas ambientais de todo o mundo (CONDE et al., 2014). A média da geração per capita de resíduos sólidos se altera em função de fatores culturais, hábito de consumo, padrão de vida e a renda familiar, que define o poder de compra (BIDONE et al., 2009).

A decomposição dos resíduos resulta na produção de um líquido conhecido como chorume (MIYAGAWA et al., 2016), que segundo Costa (2004) e Lessa (2017) este liquido advindo da decomposição da matéria orgânica e de produtos químicos tóxicos disseminados nos resíduos pode ser carreado por via superficial até os rios, onde é incorporado à água e também pode penetrar no solo e atingir águas subterrâneas. Devido a esta problemática, existe uma grande preocupação dos órgãos públicos e ambientais com a destinação final desse número cada vez maior de resíduos. No Brasil foi instituída a Política Nacional de Resíduos Sólidos, lei no 12.305 de 2 de agosto de 2010, com diretrizes relativas à gestão integrada e ao gerenciamento e destinação adequada de resíduos sólidos (BRASIL, 2010).

No Brasil, no ano de 2018 foram geradas 79 milhões de toneladas de resíduos sólidos urbanos, no qual $92 \%$ ( 72,7 milhões) foi coletado e deste montante, somente $59,5 \%$ foram destinados adequadamente em aterros sanitários, um equivalente a 43,3 milhões de toneladas. O restante $(40,5 \%)$ foi despejado em locais inadequados distribuídos por 3.001 municípios em lixões ou aterros controlados (ABRELPE, 2019).

No município de Santarém, Região Oeste do Estado do Pará, os resíduos produzidos pela população são depositados em um aterro controlado a aproximadamente $14 \mathrm{Km}$ do centro urbano. $\mathrm{O}$ aterro controlado entrou em funcionamento sem parecer técnico de profissionais. Os resíduos sólidos não eram enterrados como determina a legislação sanitária, principalmente no período chuvoso (OLIVEIRA et al., 2014).

Diante do exposto, o presente trabalho teve como objetivo avaliar a qualidade das águas superficiais e subterrâneas do entorno do aterro controlado do município de Santarém e identificar a presença de compostos nocivos ao meio ambiente, como metais pesados no solo do aterro.

\section{MATERIAIS E MÉTODOS}

\section{Área de estudo}

O estudo foi realizado no aterro controlado do município de Santarém, conhecido como "Aterro do Perema". O município está localizado na Região Oeste do Estado do Pará, possui uma população de aproximadamente 302.667 mil habitantes, estimado para o ano de 2018 em uma área de 17.898,389 km² (IBGE, 2010). O aterro localiza-se na Comunidade do Perema distante a aproximadamente $14 \mathrm{Km}$ do centro da Cidade, no Km 15 da Rodovia PA- 370, a Santarém - Curuá-Uma (Figura 1). Possui uma área de 68 hectares, e no seu entorno estão as comunidades de Castela, Miritituba, Mararu, Perema, Estrada Nova e Cristo Rei (CRUZ et al., 2017). 


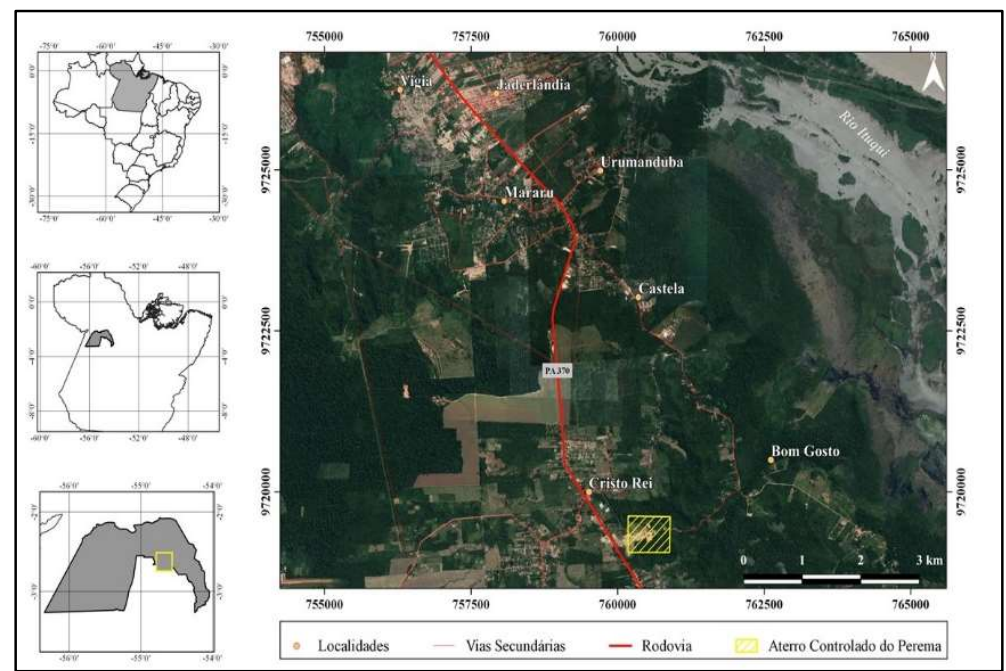

Figura 1: Mapa de localização do Aterro Sanitário do Perema.

\section{Amostragem e Coleta}

Para a avaliação da qualidade das águas superficiais foram coletadas amostras de água em dois diferentes pontos: i) Igarapé do Cararazinho, no entorno do aterro, possui mata ciliar preservada de aproximadamente $50 \mathrm{~m}^{2}$ de extensão, estando a jusante do aterro, possuindo as seguintes coordenadas $\mathrm{S}$ 02 32' 12.9” W 054 39'03.0”; ii) Ponte na comunidade de Castela, localizada a aproximadamente 1000

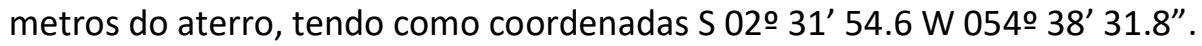

As coletas das amostras das águas superficiais foram realizadas conforme o preconizado pela Associação Brasileira de Normas Técnicas, NBR 9898, de junho 1987, a qual estabelece condições para a coleta e a preservação de amostras de água, de corpos receptores interiores superficiais (ABNT, 1987).

As amostras para a avaliação das propriedades físico-químicas das águas subterrâneas, foram coletadas em um poço nas dependências da Escola Municipal de Ensino Infantil Emílio Rabelo dos Santos/Santarém-PA, localizada nas seguintes coordenadas S 02 31’ 47.0” W 054 38' 35.5”.

Para a coleta da água subterrânea proveniente do poço, foram utilizados os procedimentos estabelecidos pelo Ministério da Saúde a partir da publicação das “Orientações Técnicas para Coleta, Acondicionamento e Transporte de Amostras de Água para Consumo Humano” publicada em abril de 2013 (BRASIL, 2013).

Dentro do aterro, existem duas lagoas de chorume de onde foram coletadas amostras do líquido, conforme a NBR 9898. Também foram coletadas amostras de solo próximo as lagoas para se avaliar a presença de metais no solo e a influência desses parâmetros nas lagoas.

As coletas das amostras de solo foram realizadas em dois pontos do aterro controlado, localizados próximos as lagoas. Sendo realizada como auxílio de um trado na camada subsuperficial do solo, a uma profundidade de $20 \mathrm{~cm}$ (ARRUDA et al., 2014), todas as amostras foram realizadas em duplicata, tanto na água superficial, quanto na água subterrânea e chorume.

\section{Análise dos Parâmetros físico-químicos da água}

Após as coletas, as amostras de água foram devidamente armazenadas e conduzidas ao Laboratório 
de Química Aplicada a Toxicologia, Saneamento Ambiental e Recursos Hídricos da Universidade Federal do Oeste do Pará. No laboratório foram analisadas as concentrações de nitrito $\left(\mathrm{NO}_{2}\right)$, nitrato $\left(\mathrm{NO}_{3}{ }^{-}\right)$, amônia $\left(\mathrm{NH}_{3}\right)$, amônio $\left(\mathrm{NH}_{4}{ }^{+}\right)$, fosfato $\left(\mathrm{PO}_{4}{ }^{3-}\right)$, sulfato, potássio $(\mathrm{K})$ e demanda química de oxigênio (DQO) (Tabela). Outros parâmetros como oxigênio dissolvido $(O D)$, temperatura da Água, turbidez, condutividade elétrica, $\mathrm{pH}$, sólidos totais dissolvidos (STD) foram analisados in loco.

Tabela 1: Métodos analíticos para a determinação dos parâmetros físico-químicos.

\begin{tabular}{|c|c|c|c|}
\hline Variável & Modelo & $\begin{array}{ll}\text { Faixa } & \text { de } \\
\text { Detecção } & \\
\end{array}$ & Método \\
\hline OD & Oxímetro (55 YSI) & 0 a $20 \mathrm{mg} / \mathrm{L}$ & Galvânico, Clark (níquel/chumbo) \\
\hline Temperatura & Oxímetro (55 YIS) & -5 a $45 \circ C$ & Galvânico, Clark (níquel/chumbo) \\
\hline Turbidez & Turbidímetro (AP 200 PoliControl) & 0,0 a 1000 NTU & $\begin{array}{l}\text { Arnold O. Beckman, } 1940 \\
\text { (espectrofotométrico) Nefelométrico }\end{array}$ \\
\hline $\begin{array}{l}\text { Condutividade } \\
\text { Elétrica }\end{array}$ & Condutivímetro (EC 300 EcoSense) & 0 a $499,9 \mu \mathrm{S} / \mathrm{cm}$ & $\begin{array}{l}\text { Karl Fischer, } 1935 \\
\text { (Eletrométrico) }\end{array}$ \\
\hline pH & Phmetro (60 YSI) & 0 a 14 & $\begin{array}{l}\text { Karl Fischer, } 1935 \\
\text { (Eletrométrico) }\end{array}$ \\
\hline STD & Condutivímetro (EC 300 EcoSense) & 0,30 a 1,00 & $\begin{array}{l}\text { Karl Fischer, } 1935 \\
\text { (Eletrométrico) }\end{array}$ \\
\hline DQO & $\begin{array}{l}\text { Fotômetro Multiparamétrico (HI } 83099 \\
\text { Hanna) }\end{array}$ & 0 a $150 \mathrm{mg} / \mathrm{L}$ & $\begin{array}{l}\text { Arnold O. Beckman, } 1940 \\
\text { Dicromato, Sulfato de Mercúrio } \\
\text { (espectrofotométrico) }\end{array}$ \\
\hline Amônia & $\begin{array}{l}\text { Fotômetro Multiparamétrico (HI } 83099 \\
\text { Hanna) }\end{array}$ & 0.0 a $3.00 \mathrm{mg} / \mathrm{L}$ & $\begin{array}{l}\text { Arnold O. Beckman, } 1940 \\
\text { (espectrofotométrico)Nessler }\end{array}$ \\
\hline Nitrito & $\begin{array}{l}\text { Fotômetro Multiparamétrico (HI } 83099 \\
\text { Hanna) }\end{array}$ & 0.0 a $1.15 \mathrm{mg} / \mathrm{L}$ & $\begin{array}{l}\text { Arnold O. Beckman, } 1940 \\
\text { (espectrofotométrico) Diazotação. }\end{array}$ \\
\hline Nitrato & $\begin{array}{l}\text { Fotômetro Multiparamétrico (HI } 83099 \\
\text { Hanna) }\end{array}$ & 0.0 a $30.0 \mathrm{mg} / \mathrm{L}$ & $\begin{array}{l}\text { Arnold O. Beckman, } 1940 \\
\text { (espectrofotométrico)Redução } \\
\text { cádmio. }\end{array}$ \\
\hline Sulfato & $\begin{array}{l}\text { Fotômetro Multiparamétrico (HI } 83099 \\
\text { Hanna) }\end{array}$ & 0 a $100 \mathrm{mg} / \mathrm{L}$ & $\begin{array}{l}\text { Foster, } 1942 \\
\text { Turbidimétrico }\end{array}$ \\
\hline Potássio & $\begin{array}{l}\text { Fotômetro Multiparamétrico (HI } 83099 \\
\text { Hanna) }\end{array}$ & 0.0 a $20.0 \mathrm{mg} / \mathrm{L}$ & $\begin{array}{l}\text { Foster, } 1942 \\
\text { Turbidimétrico }\end{array}$ \\
\hline Fosfato & $\begin{array}{l}\text { Fotômetro Multiparamétrico (HI } 83099 \\
\text { Hanna) }\end{array}$ & 0.0 a $2.50 \mathrm{mg} / \mathrm{L}$ & Ácido Ascórbico \\
\hline
\end{tabular}

\section{Análise dos Parâmetros físico - químicos e metais pesados presente no chorume}

As análises dos parâmetros físico-químico do chorume seguem o mesmo procedimento metodológico estabelecido na Tabela 1. Foram analisados os seguintes parâmetros físico-químicos: nitrito $\left(\mathrm{NO}_{2}{ }^{-}\right)$, nitrato $\left(\mathrm{NO}_{3}{ }^{-}\right)$, nitrogênio de amônia $\left(\mathrm{NH}_{3}{ }^{-}-\mathrm{N}\right)$, Amônia $\left(\mathrm{NH}_{3}\right)$, fosforo $(\mathrm{P})$, ferro $(\mathrm{Fe})$, zinco $(\mathrm{Zn})$, DQO, $\mathrm{pH}$, turbidez, Oxigênio dissolvido (OD). Os metais pesados foram analisados com o auxílio da sonda Metalyser Portable HM 1000, seguindo o procedimento de Voltamperometria de Archie Hickling (1942) sendo analisados os seguintes metais pesados: cádmio $(\mathrm{Cd})$, mercúrio $(\mathrm{Hg})$, cobre $(\mathrm{Cu})$.

\section{Análises de espectrometria por energia dispersiva no chorume (EDS)}

Após a coleta, as amostras de chorume foram secas (naturalmente) e maceradas manualmente no cadinho. Após esse procedimento as amostras foram encaminhadas ao Laboratório de Microscopia Eletrônica de Varredura (Labmev), da Universidade Federal do Pará, para se avaliar a presença de metais no chorume, por espectrometria de energia dispersiva - EDS (swiftED 3000 X-RAY) acoplado ao microscópio eletrônico de varredura- MEV (MEV 3000, HITACHI). Esse sistema permite realizar uma a análise qualitativa 
e quantitativa dos elementos de interesse das amostras e a composição química dos constituintes presentes na amostra.

\section{Análise dos dados}

Os resultados das águas superficiais foram comparados com a legislação vigente do Conselho Nacional de meio Ambiente (CONAMA), utilizando a resolução № 357 que estabelece a classificação dos corpos de água e diretrizes ambientais para o seu enquadramento, bem como estabelece as condições e padrões de lançamento de efluentes, além de providências para as águas superficiais (CONAMA, 2005).

Para as águas subterrâneas foi utilizado a Portaria de Consolidação do Ministério da Saúde № 5 que preconiza os procedimentos de controle e de vigilância da qualidade da água para consumo humano e seu padrão de potabilidade (BRASIL, 2017).

Para avaliar os resultados do chorume, foi utilizada a resolução $N^{\circ} 430$ do CONAMA, que dispõe sobre as condições e padrões de lançamento de efluentes, complementa e altera a Resolução № 357 (CONAMA, 2011). Os dados provenientes das análises de espectrometria foram calculados estatísticas descritivas (médias e porcentagens).

\section{RESULTADOS E DISCUSSÃO}

\section{Análises de água superficial e subterrânea}

Os resultados das análises físicas-químicas das águas superficiais dos dois pontos de coleta do igarapé Cararazinho, próximo ao aterro sanitário, foi analisado em consonância com que preconiza a Resolução 357/2005, do Conselho Nacional de Meio Ambiente - CONAMA. Observamos variação significativas, nas concentrações de nitrato, turbidez e pH, fora dos padrões de qualidade de água conforme apresentado na Tabela 2.

Os valores de pH obtidos nos dois pontos de coleta estão em discordância com o exigido pela legislação ambiental vigente, apresentando valores de 5,4 e 4,67 na área florestada e antropizada respectivamente. Com base nesses resultados, a água está inapropriada para qualquer um dos usos atribuídos as classes estabelecidas na resolução CONAMA № 357, que define as classes de água, utilizada nesse estudo.

$\mathrm{O}$ pH é uma variável abiótica importante nos ecossistemas aquáticos de difícil interpretação, pois pode sofrer alteração por diversos fatores (ESTEVES, 2011). Alguns podem ser naturais devido a dissolução de rochas e processos fotossintéticos, mas também sofrem expressiva influência de fatores antrópicos como a disposição de esgotos domésticos e industriais (VON SPERLING, 2014). Na região Amazônica o pH das águas do Aquífero Alter do Chão apresenta características ácidas, sendo, portanto, uma característica comum das águas da região, o que pode ser justificado, devido sua constituição mais siliciclásticas (areias e argilas) que dão um conteúdo mais rico em sílica (IMBIRIBA et al., 2012).

Na Tabela 2, observa-se que a turbidez da água no ponto I, apresentou valores fora do estabelecido 
pela legislação, sendo encontrado o valor de 105 NTU, acima do máximo permitido, para as três classes. A elevação da turbidez no ponto I, pode provocar atenuação da luz no meio aquoso e comprometer o metabolismo dos organismos fotossintetizantes (KUHN et al., 2015), contribuindo efetivamente para uma significativa redução na taxa de produtividade primária com a redução da penetração de luz (ESTEVES, 1998).

Ainda de acordo com Esteves (1998), a presença do ferro no ponto I, pode se dá devido ao carreamento de solo argiloso o que pode constituir várias frações dos minerais secundários, que apresentam grande capacidade de adsorção de fosfato, principalmente aquelas que têm, na sua constituição, ferro e alumínio, como hematita e gipsita.

E o nitrato em excesso no mesmo ponto, favorece o crescimento descontrolado das populações de algas e plantas aquáticas (eutrofização), induzindo o aparecimento de odores e gosto na água, pois ao se decomporem, consomem grandes quantidades de oxigênio (KEMERICH et al., 2012), fato observado no ponto I. A concentração de nitrato fora do estabelecido na resolução vigente, podem alterar seu sabor e contribuir para corrosão do sistema de distribuição e ainda dificultando a descontaminação da água (PHILIPPI JUNIOR, 2004; MACIEL, 2019).

Tabela 2: Resultados das análises físicas e químicas da água superficial dos pontos de influência do aterro do Perema, Santarém-PA comparados com os valores máximos estabelecidos pela legislação vigente.

\begin{tabular}{|c|c|c|c|c|c|}
\hline Parâmetros & $\begin{array}{l}\text { Classe } 1 \\
\text { VMP }\end{array}$ & Classe 2 VMP & $\begin{array}{l}\text { Classe } 3 \\
\text { VMP } \\
\end{array}$ & $\begin{array}{l}\text { Ponto I } \\
\text { (Floresta) }\end{array}$ & $\begin{array}{l}\text { Ponto II } \\
\text { (Antropizada) }\end{array}$ \\
\hline Salinidade & $0,5 \%$ & $0,5 \%$ & $0,5 \%$ & $0,00 \mathrm{mg} / \mathrm{L}$ & $0,00 \mathrm{mg} / \mathrm{L}$ \\
\hline TDS & $500 \mathrm{mg} / \mathrm{L}$ & $500 \mathrm{mg} / \mathrm{L}$ & $500 \mathrm{mg} / \mathrm{L}$ & $42,3 \mathrm{mg} / \mathrm{L}$ & $8,9 \mathrm{mg} / \mathrm{L}$ \\
\hline $\mathrm{pH}$ & 6,0 a 9,0 & 6,0 a 9,0 & 6,0 a $9,0$. & 5,41 & 4,67 \\
\hline Turbidez & $\leq 40$ UNT & 100 UNT & 100 UNT & 105 NTU & $0,02 \mathrm{NTU}$ \\
\hline Nitrito $\left(\mathrm{NO}_{2}{ }^{-}\right)$ & $1,0 \mathrm{mg} / \mathrm{L}$ & $1,0 \mathrm{mg} / \mathrm{L}$ & $1,0 \mathrm{mg} / \mathrm{L}$ & $0,01 \mathrm{mg} / \mathrm{L}$ & $0,12 \mathrm{mg} / \mathrm{L}$ \\
\hline Nitrato $\left(\mathrm{NO}_{3}{ }^{-}\right)$ & $10,0 \mathrm{mg} / \mathrm{L}$ & $10,0 \mathrm{mg} / \mathrm{L}$ & $10,0 \mathrm{mg} / \mathrm{L}$ & $14,7 \mathrm{mg} / \mathrm{L}$ & $0,00 \mathrm{mg} / \mathrm{L}$ \\
\hline Amônio $\left(\mathrm{NH}_{4}{ }^{+}\right)$ & -- & -- & -- & $0,63 \mathrm{mg} / \mathrm{L}$ & $0,22 \mathrm{mg} / \mathrm{L}$ \\
\hline Fosforo (P) & $0,020 \mathrm{mg} / \mathrm{L}$ & $0,020 \mathrm{mg} / \mathrm{L}$ & $0,15 \mathrm{mg} / \mathrm{L}$ & $0,00 \mathrm{mg} / \mathrm{L}$ & $0,00 \mathrm{mg} / \mathrm{L}$ \\
\hline Ferro (Fe) & $0,3 \mathrm{mg} / \mathrm{L}$ & $0,3 \mathrm{mg} / \mathrm{L}$ & $5,0 \mathrm{mg} / \mathrm{L}$ & $4,48 \mathrm{mg} / \mathrm{L}$ & $0,13 \mathrm{mg} / \mathrm{L}$ \\
\hline Zinco (Zn) & $0,18 \mathrm{mg} / \mathrm{L}$ & $0,18 \mathrm{mg} / \mathrm{L}$ & $5 \mathrm{mg} / \mathrm{L}$ & $0,01 \mathrm{mg} / \mathrm{L}$ & $0,00 \mathrm{mg} / \mathrm{L}$ \\
\hline Oxigênio Dissolvido (OD) & $\geq$ a $5 \mathrm{mg} / \mathrm{L}$ & $\geq a 5 \mathrm{mg} / \mathrm{L}$ & $\geq 4 \mathrm{mg} / \mathrm{L}$ & $4,32 \mathrm{mg} / \mathrm{L}$ & $3,34 \mathrm{mg} / \mathrm{L}$ \\
\hline DQO & -- & -- & -- & $19 \mathrm{mg} / \mathrm{L}$ & $38 \mathrm{mg} / \mathrm{L}$ \\
\hline TDS (Sólidos dissolvidos totais) & $500 \mathrm{mg} / \mathrm{L}$ & $500 \mathrm{mg} / \mathrm{L}$ & $500 \mathrm{mg} / \mathrm{L}$ & $42,3 \mathrm{mg} / \mathrm{L}$ & $8,9 \mathrm{mg} / \mathrm{L}$ \\
\hline Condutividade & -- & -- & -- & 64,7 uS & $13,8 \mathrm{uS}$ \\
\hline
\end{tabular}

VMP=Valor Máximo Permitido.

Na Tabela 3 estão apresentados os resultados das análises físico-químicas da água subterrânea da área de influência do aterro do Perema, Santarém-PA. Observa-se que o pH $(3,82)$ e a concentração de nitrato $\left(34,7 \mathrm{mg} \mathrm{L}^{-1}\right)$ encontram-se acima dos valores máximos permitidos pela Portaria de consolidação № 5 do Ministério da Saúde, no qual dispõe sobre os procedimentos de controle e de vigilância da qualidade da água para consumo humano e seu padrão de potabilidade (BRASIL, 2017). Como já discutido anteriormente, o pH ácido, pode ser devido as formações sedimentares da região.

Concentrações de nitrato acima do estabelecido para o consumo humano, pode resultar em danos à saúde. No organismo humano, o nitrato converte-se em nitrito que se liga com a hemoglobina para formar metahemoglobina, e com isso, evita o transporte de oxigênio no sangue (MAGALHÃES, 2015; ROSA et al., 2020). A amônia e o nitrito, costumam estar ausente na água, pois são rapidamente convertidos em nitrato pelas bactérias, justificando assim as baixas concentrações encontradas desses componentes nos pontos de 
coleta de água (ARAUJO et al., 2013).

Tabela 3: Resultados das análises físicas e químicas da água subterrânea da área de influência do aterro do Perema, Santarém-PA.

\begin{tabular}{lll}
\hline Parâmetros & VMP & Água Subterrânea \\
\hline pH & 6 e 9 & 3,82 \\
Turbidez & $5 \mathrm{NTU}$ & $0,02 \mathrm{NTU}$ \\
Nitrito $\left(\mathrm{NO}_{2}{ }^{-}\right)$ & $1 \mathrm{mg} / \mathrm{L}$ & $0,06 \mathrm{mg} / \mathrm{L}$ \\
Nitrato $\left(\mathrm{NO}_{3}{ }^{-}\right)$ & $10 \mathrm{mg} / \mathrm{L}$ & $34,7 \mathrm{mg} / \mathrm{L}$ \\
Nitrogênio de amônia $\left(\mathrm{NH}_{3}-\mathbf{N}\right)$ & $3,7 \mathrm{mg} / \mathrm{L} \mathrm{N}$, para $\mathrm{pH} \leq 7,5$ & $0,28 \mathrm{mg} / \mathrm{L}$ \\
Amônia $\left(\mathrm{NH}_{3}\right)$ & $1,5 \mathrm{mg} / \mathrm{L}$ & $0,34 \mathrm{mg} / \mathrm{L}$ \\
Fosforo $(\mathbf{P})$ & $0,020 \mathrm{mg} / \mathrm{L}$ & $0,00 \mathrm{mg} / \mathrm{L}$ \\
Ferro $(\mathrm{Fe})$ & $0,3 \mathrm{mg} / \mathrm{L}$ & $0,00 \mathrm{mg} / \mathrm{L}$ \\
Zinco $(\mathrm{Zn})$ & $5 \mathrm{mg} / \mathrm{L}$ & $0,01 \mathrm{mg} / \mathrm{L}$ \\
\hline
\end{tabular}

VMP= Valor Máximo Permitido.

\section{Análises do chorume}

Na Tabela 4 estão apresentados os valores das concentrações dos parâmetros físico-químicos e de metais pesados do chorume proveniente do aterro sanitário do Perema. Os resultados das análises físicoquímicas do chorume mostram que as concentrações de nitrato, amônia, fósforo, DQO, turbidez e OD estão fora do padrão para a disposição de efluentes. Dentre os metais pesados avaliados, o mercúrio foi o único que apresentou concentrações acima dos padrões estabelecidos para disposição de efluente, segundo a resolução № 430 do CONAMA.

No ambiente aquático, o mercúrio inorgânico é associado em solução e em suspensão por diversos ligantes geoquímicos: ácidos orgânicos, sais, Fe e Mn oxi-hidróxidos, minerais argilosos, matéria orgânica dissolvida, entre outros (CARDONA, 2015; MIRANDA, 2019).

Os resíduos compostos de plástico, metal e outros materiais orgânicos produzem um chorume rico em metais pesados, e a alta retenção desses metais se dá provavelmente devido à condição inerte dos metais em sua origem estado sólido depositado ( $\varnothing$ YGARD et al., 2004). Estes resultados demostram que o manejo e tratamento do chorume está fora dos padrões estabelecidos pela Lei № 12.305/10, que institui a Política Nacional de Resíduos Sólidos (PNRS), podendo se tornar uma potencial fonte poluidora de corpos hídricos ao longo do tempo, já sendo observado alterações nas concentrações de nitrato nas amostras de água, como mostram os resultados anteriores deste estudo (BRASIL, 2010).

A área de estudo do aterro controlado, não possui estruturas de um aterro sanitário, e as lagoas onde são armazenadas o chorume sofrem influência direta da precipitação local, possuindo ainda, solo sem cobertura apropriada para o recebimento do chorume. Com isso os resultados obtidos podem não representar a realidade dos parâmetros analisados para o chorume.

Tabela 4: Análises físico-químicas e de metais pesados do chorume.

\begin{tabular}{llll}
\hline Análises $(\mathbf{m g} / \mathrm{L})$ & VMP & Ponto $\mathbf{0 2}$ & Ponto 03 \\
\hline Nitrito $\left(\mathbf{N O}_{2}^{-}\right)$ & $1 \mathrm{mg} / \mathrm{L}$ & $1,13 \mathrm{mg} / \mathrm{L}$ & -- \\
Nitrato $\left(\mathbf{N O}_{3}{ }^{-}\right)$ & $10 \mathrm{mg} / \mathrm{L}$ & -- & -- \\
Nitrogênio de amônia $\left(\mathbf{N H}_{3}{ }^{-}-\mathbf{N}\right)$ & $20,0 \mathrm{mg} / \mathrm{L}$ & $5,48 \mathrm{mg} / \mathrm{L}$ & $4,61 \mathrm{mg} / \mathrm{L}$ \\
Amônia $\left(\mathbf{N H}_{3}\right)$ & -- & $6,66 \mathrm{mg} / \mathrm{L}$ & $5,61 \mathrm{mg} / \mathrm{L}$ \\
Fosforo $(\mathbf{P})$ & $0,1 \mathrm{mg} / \mathrm{L} \mathrm{P}-$ Classe $1 \mathrm{e} 2$ & $1,6 \mathrm{mg} / \mathrm{L}$ & $0,2 \mathrm{mg} / \mathrm{L}$ \\
Ferro (Fe) & $0,15 \mathrm{mg} / \mathrm{L} \mathrm{P}-$ Classe 3 & $1,36 \mathrm{mg} / \mathrm{L}$ & $0,88 \mathrm{mg} / \mathrm{L}$
\end{tabular}




\begin{tabular}{|c|c|c|c|}
\hline Zinco (Zn) & $5,0 \mathrm{mg} / \mathrm{L}$ & $0,00 \mathrm{mg} / \mathrm{L}$ & $0,00 \mathrm{mg} / \mathrm{L}$ \\
\hline DQO & -- & $1993 \mathrm{mg} / \mathrm{L}$ & $1266 \mathrm{mg} / \mathrm{L}$ \\
\hline pH & Entre 6,0 e 9,0 & 8,76 & 8,74 \\
\hline Turbidez & $\begin{array}{l}100 \mathrm{NTU} \\
>6 \mathrm{mg} / \mathrm{L} \mathrm{O}_{2} \text {. Classe } 1\end{array}$ & 235 NTU & 572NTU \\
\hline OD & $\begin{array}{l}>5 \mathrm{mg} / \mathrm{L} \mathrm{O}_{2}-\text { Classe } 2 \\
>>4 \mathrm{mg} / \mathrm{L} \mathrm{O}_{2}-\text { Classe } 3\end{array}$ & $1,5 \mathrm{mg} / \mathrm{L}$ & $0,1 \mathrm{mg} / \mathrm{L}$ \\
\hline Cd & 0,2 & $<\mathrm{FL}$ & $<\mathrm{FL}$ \\
\hline $\mathrm{Hg}$ & 0,01 & 0,24826 & $<\mathrm{FL}$ \\
\hline $\mathrm{Cu}$ & 1,0 & $<\mathrm{FL}$ & 0,04277 \\
\hline
\end{tabular}

VMP=Valor máximo permitido; $<$ FL=Menor que a faixa de leitura; $>$ FL=Maior que a faixa de leitura.

\section{Análises de Espectroscopia de energia dispersiva (EDS) do solo}

Na Figura 2 está apresentado o espectro global da composição da amostra gerada por EDS. Através da espectroscopia de energia dispersiva (EDS) foi detectado que os elementos predominantes nas amostras foram: oxigênio (O), alumínio (Al), titânio (Ti), ferro (Fe) e silício (Si), apresentando os maiores espectros.

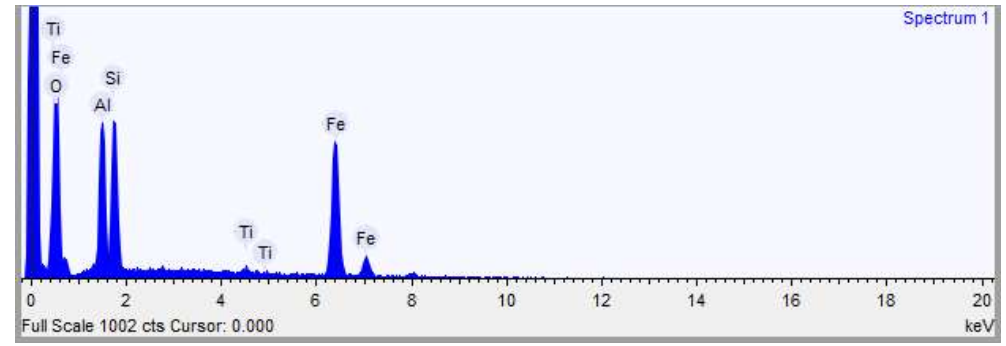

Figura 2: Espectro global da composição da amostra de solo gerado por EDS (espectroscopia de energia dispersiva).

Na Tabela 5 estão apresentados os elementos minerais encontrados resultados das do Aterro sanitário do Perema. Foram encontrados alumínio, silício, titânio e ferro em quantidades expressivas, com elevada concentração de ferro e titânio na amostra de solo da lagoa 1 quando comparada com a lagoa 2. A quantidade de alumínio e oxigênio encontrado no solo das duas lagoas foram aproximados, no entanto, observa-se um significativo aumento de contração silício na lagoa 2. Em média os metais detectados apresentaram as seguintes proporções: $\mathrm{Ti}<\mathrm{Fe}<\mathrm{AK}<\mathrm{Si}$.

A presença de alguns elementos no solo, por si só não são motivo de preocupação, pois sua biodisponibilidade é essencial e/ou benéfica para o crescimento e desenvolvimento de vegetais como, por exemplo, o ferro (Fe) e silício (Si). O alumínio (Al) é o terceiro elemento mais abundante na litosfera, fazendo parte de $8 \%$ da composição da crosta terrestre, estando presente em diferentes formas no solo. Na região amazônica, os solos são ácidos com elevado teor de alumínio (Al) trocável, sendo a presença do elemento característica normal destes solos (ROSSIELLO et al., 2006; HARIDASAN, 2006).

Entretanto, em áreas potencialmente poluidoras, como o aterro controlado, a migração de lixiviados no solo pode contribuir para a contaminação do solo com, gerando sérios problemas ao meio ambiente (SOUZA, 2016). Desta forma, as presenças destes metais devem ser avaliadas com cautela, pois diversos resíduos têm grande potencialidade de contaminação devido possuírem grandes quantidades destes elementos e, quando decompostos, podem vir a contaminar o solo.

De acordo com Gouveia (2015) e Santos et al. (2015) as principais fontes de contaminação de resíduos urbanos em lixões e aterros são: ferro (Fe) são materiais eletrônicos, latas e tampas de garrafas; de 
alumínio (Al) latas descartáveis, cosméticos e embalagens laminadas em geral e de silício.

Tabela 5: Composição química e valores percentuais das amostras de solo do aterro, com base nos elementos mais representativos.

\begin{tabular}{llllll}
\hline Elementos (\%) & $\mathbf{0}$ & Al & Si & Ti & Fe \\
\hline Lagoa 1 & 55,22 & 14,30 & 13,68 & 0,88 & 8,60 \\
Lagoa 2 & 58,35 & 17,15 & 20,79 & 0,76 & 2,91 \\
\hline
\end{tabular}

\section{CONCLUSÕES}

Conforme a Resolução 357/2005 (BRASIL, 2005) do Conselho Nacional de Meio Ambiente- CONAMA, a água superficial do igarapé do Cararazinho, foi considerada inapropriada para quaisquer que fosse sua atribuição, devido as altas concentrações de nitrato e ferro, além de um dos pontos a turbidez se mostra bastante elevada, assim como o pH que se encontra abaixo do estabelecido para as classes de água. Os parâmetros que estão em desconformidade com os estabelecidos pela portaria de consolidação $n$ 으, 5 , da água do poço são o pH e a concentração de nitrato. Sendo assim, as águas estão impróprias para os usos ou atribuições segundo a legislação vigente.

As análises físico-químicas das lagoas de chorume também estão fora dos padrões estabelecidos pela Resolução 430 e 357 do CONAMA, com concentrações de nitrato, amônia, fósforo e mercúrio acima do permitido. A análise quali-quantitativa de solo mostrou que os elementos predominantes foram alumínio (Al), titânio (Ti), ferro (Fe) e silício (Si).

\section{REFERÊNCIAS}

ABNT. Associação Brasileira de Normas Técnicas. NBR 9898 de junho de 1987. Dispõe de Preservação e técnicas de amostragem de efluentes líquidos e corpos receptores. Rio de Janeiro: ABNT, 1987.

ABRELPE. Associação Brasileira de Empresas de Limpeza Pública E Resíduos Especiais. Panorama de resíduos sólidos no Brasil 2018/2019, São Paulo: ABRELPE, 2019.

ARAUJO, C. F.; HIPÓLITO, J. R.; WAICHMAN, A. V.. Avaliação da qualidade da água de poço. Revista do Instituto Adolfo Lutz, v.72, n.1, p.53-58, 2013.

ARRUDA, M. R.; MOREIRA, A.; PEREIRA, J. C. R.. Amostragem e cuidados na coleta de solo para fins de fertilidade. Manaus: Embrapa Amazônia Ocidental, 2014.

BIDONE, F. R. A.; POVINELLI, J.. Conceitos básicos de resíduos sólidos. São Carlos: USP, 1999.

BRASIL. Lei no 12.305, de 2 de agosto de 2010. Institui a Política Nacional de Resíduos Sólidos; altera a Lei no 9.605, de 12 de fevereiro de 1998 e dá outras providências. Brasília: DOU, 2010.

BRASIL. Ministério da Saúde. Orientações técnicas para coleta, acondicionamento e transporte de amostras de água para consumo humano. Brasília: Ministério da Saúde, 2013.

BRASIL. Ministério da Saúde. Portaria de Consolidação no 5, de 28 de setembro de 2017. Dispõe consolidação das normas sobre as ações e os serviços de saúde do Sistema Único de Saúde. Brasília: DOU, 2018.

CARDONA, M. T.. Determinação in situ de metilmercúrio e mercúrio (II) em sistemas aquáticos nas proximidades de refinarias de petróleo, utilizando a técnica difusão em filmes finos por gradiente de concentração (DGT). Dissertação (Mestrado em Geociência e Meio Ambiente) Universidade Estadual Paulista, Rio Claro, 2015.

CONAMA. Conselho Nacional de Meio Ambiente. Resolução n. 357, de 17 de março de 2005. Brasília: DOU, 2005.

CONAMA. Conselho Nacional de Meio Ambiente. Resolução n. 430, de 13 de maio de 2011. Brasília: DOU, 2011.

CONDE, T. T.; STACHIW, R.; FERREIA, E.. Aterro sanitário como alternativa para a preservação ambiental. Revista Brasileira de Ciências da Amazônia, v.3, n.1, p.69-80, 2014.

COSTA, W. D.. Contaminação da água subterrânea por resíduo sólido no município de Belo Horizonte/MG. Águas Subterrâneas, n.1, 2004.

CRUZ, S. L. F.; GOMES, M. V. C. N.; BLANCO, C. J. C.. Trabalho e Resíduos: Uma investigação sobre os catadores de lixo de um aterro controlado na Amazônia. Revista Gestão \& Sustentabilidade Ambiental, v.6, n.2, p.351-367, 2017. DOI: http://dx.doi.org/10.19177/rgsa.v6e22017351-367

ESTEVES, F.. Fundamentos de limnologia. 2 ed. Rio de Janeiro: Interciência. 1998. 
ESTEVES, F.. Fundamentos de limnologia. 3. ed. Rio de Janeiro: Interciência, 2011.

GOUVEIA, N.. Resíduos sólidos urbanos: impactos socioambientais e perspectiva de manejo sustentável com inclusão social. Ciência \& Saúde Coletiva, v.17, n.6, pp.15031510, 2012. DOI: https://doi.org/10.1590/S1413$\underline{81232012000600014}$

HARIDASAN, M.. Alumínio é um elemento tóxico para as plantas nativas do cerrado?. In: PRADO, C. H. B. A.; CASALI, C. A.. Fisiologia Vegetal: práticas em relações hídricas, fotossíntese e nutrição mineral. Barueri: Manole, 2006. p.110.

IBGE. Instituto Brasileiro de Geografia e Estatística. Estimava populacional: Município de Santarém. Brasília: IBGE, 2010.

IMBIRIBA JUNIOR, M.; HOMERO JUNIOR, R. M.. Aquífero Alter Do Chão: análises químicas in loco dos poços construídos pela Rimas (SGB-CPRM). Águas Subterraneas, n.1, 2012

KEMERICH, D. C.; SILVA, R. F.; REQUE, P. T.. Determination of the index of water quality in Esperance stream. Ciência e Natureza, v.34, n.2, p.83-98, 2012._DOI: http://dx.doi.org/10.5902/2179460x9343

KUHN, D.; REISDÖRFER, G.. Avaliação da eficiência da aplicação de coagulante orgânico em chorume para remoção de carga orgânica e nutrientes. Tecno-Lógica, v.19, n.2, p.6468, 2015. DOI:

http://dx.doi.org/10.17058/tecnolog.v19i2.5460

LESSA, A. C. V.. Caracterização do chorume do Centro de Gerenciamento de Resíduos de Sergipe. Monografia (Bacharelado em Tecnólogo em Saneamento Ambiental) Instituto Federal de Sergipe, Aracaju, 2017.

MACIEL, J. R. F.. Influência da água no processo de corrosão em tubulações de ETAs e redes de distribuição. Monografia (Bacharelado em Química) - Universidade Federal do Ceará, Fortaleza, 2019.

MAGALHÃES, H. I. F.. Riscos associados aos níveis de nitritos em alimentos: uma revisão. Monografia (Bacharelado em Farmácia) - Universidade Federal da Paraíba, João Pessoa, 2015.
MIRANDA, J. F.. Estimativa da quantidade de mercúrio usada em uma mina de ouro abandonada e avaliação das técnicas de remediação da área contaminada, em Descoberto - MG. Tese (Doutorado em Engenharia Mineral) - Universidade Federal de Ouro Preto, Ouro Preto, 2019.

MIYAGAWA, L. D. J. P. P.; MENDES, T. A. A.; MARMOS, J. L.. Caracterização da contaminação por chorume nos recursos hídricos superficiais no entorno do aterro de resíduos sólidos de Manaus/AM. Revista Geonorte, v.7, n.27, p.65-77, 2016.

OLIVEIRA, G.; SILVA, E.. Biodigestor: Uma proposta de aproveitamento do lixo orgânico no município de Santarém. Revista Científica Semana Acadêmica, Fortaleza, v.1, 2014.

$\varnothing$ YGARD, J. K.; MÅGE, A.; GJENGEDAL, E.. Estimation of the mass-balance of selected metals in four sanitary landfills in Western Norway, with emphasis on the heavy metal content of the deposited waste and the leachate. Water research, v.38, n.12, p.2851-2858, 2004. DOI: https://doi.org/10.1016/j.watres.2004.03.036

PHILIPPI JUNIOR, A.; ROMÉRO, M. A.; BRUNA, G. C.. Curso de gestão ambiental. São Paulo: Manole, 2004.

ROSA, E.; GUDOLLE, C. B.; CIOCHETA, T. M.; RIBEIRO, P. F. A.. Determinação de Nitrato e Nitrito em Produtos Cárneos. Anais do Salão Internacional de Ensino, Pesquisa e Extensão, v.5, n.2, 2020.

ROSSIELLO, R. P.; NETTO, J. J.. Toxidez de alumínio em plantas: novos enfoques para um velho problema. In: Fernandes, M. S. Nutrição mineral de plantas. Viçosa: Sociedade brasileira de ciências solos, p.377-418, 2006.

SANTOS, A. T. L.; HENRIQUE, N. S.; SHHLINDWEIN, J. A.; FERREIRA, E.; STACHIW, R.. Aproveitamento da fração orgânica dos resíduos sólidos urbanos para produção de composto orgânico. Revista Brasileira de Ciências da Amazônia, v.3, n.1, p.15-28, 2015.

SOUZA, V.. Avaliação da contaminação do solo por metais tóxicos (cádmio, cromo, chumbo e alumínio) em estandes de tiro no estado do Paraná/Brasil. Tese (Doutorado em Ambiente e Desenvolvimento) - Universidade do Vale do Taquari, Lajeado, 2016.

VON SPERLING, M.. Estudos e modelagem da qualidade da água de rios. 2 ed. Belo Horizonte: Universidade Federal de Minas Gerais, 2014.

A CBPC - Companhia Brasileira de Produção Científica (CNPJ: 11.221.422/0001-03) detém os direitos materiais desta publicação. Os direitos referem-se à publicação do trabalho em qualquer parte do mundo, incluindo os direitos às renovações, expansões e disseminações da contribuição, bem como outros direitos subsidiários. Todos os trabalhos publicados eletronicamente poderão posteriormente ser publicados em coletâneas impressas sob coordenação da Sustenere Publishing, da Companhia Brasileira de Produção Científica e seus parceiros autorizados. Os (as) autores (as) preservam os direitos autorais, mas não têm permissão para a publicação da contribuição em outro meio, impresso ou digital, em português ou em tradução. 